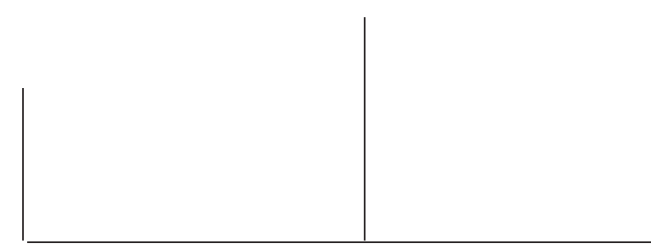

Rev. Latinoam. Psicopat. Fund., IV, 4, 112-118

\title{
O arcaico nas patologias contemporâneas. Considerações sobre o pânico*
}

\author{
Ana Maria Sigal
}

\begin{abstract}
Este trabalho aborda a questão do pânico pensado como uma falha do recalque primário. As mensagens sexuais maternas, implantadas com violência, impedem a metabolização e ficam como corpos estranhos não ligados que reaparecem sem nexo, impossibilitando sua entrada numa cadeia significante. Neste caso, os medos não são substituição de nada e, sim, a presença atual dos significantes não-metabolizados. O trabalho do analista é possibilitar que se criem novos laços onde faltou palavra.
\end{abstract}

Palavras-chave: Recalque primário, pânico, representação-coisa, angústia catastrófica

* Trabalho apresentado no V Congresso Brasileiro de Psicopatologia Fundamental, Campinas 2000. 
Num olhar atento aos trabalhos apresentados recentemente nos numerosos encontros de psicopatologia, vemos aumentado o interesse da psicanálise por certas manifestações que, até alguns anos, não demandavam nossa atenção de forma tão veemente. Esta mudança é produto do crescente número de consultas de pacientes que nos levam a refletir, pesquisar e reconsiderar nosso repertório teórico para dar conta dos problemas que hoje enfrentamos.

Nas patologias contemporâneas, podemos considerar duas vertentes fundamentais sobre as quais trabalhar: a primeira, a que se refere às condições de produção da subjetividade, ou seja, às modificações que se produzem no sujeito como decorrência do histórico-político-econômico e social; e uma segunda vertente, que se refere à própria estruturação do aparelho psíquico e que, inscrita historicamente, merece considerações metapsicológicas. Ambas as vertentes estão entremeadas e produzem efeitos de ressignificação permanente.

O consumo desenfreado, a vertiginosidade que se imprime ao tempo, que faz com que não seja possível suportar e sustentar projetos de longo prazo, o imediatismo que transforma a satisfação sem demora no leitmotiv do prazer cotidiano, a falta de solidariedade e de utopias, a política de esgotamento rápido do objeto que, conseqüentemente, não deixa marcas e impede que o mundo interno seja povoado de conteúdos próprios; a constante intervenção de uma mídia que provoca inermidade, promovendo uma passividade e transformando o sujeito em objeto, atacando os processos criativos e de pensamento; a corrupção social e o desemprego, que aprofundam o sentimento de desamparo e ruína e colocam o Eu em posição de falência, são algumas das inumeráveis mudanças histórico-político-sociais e econômicas que imprimem um 


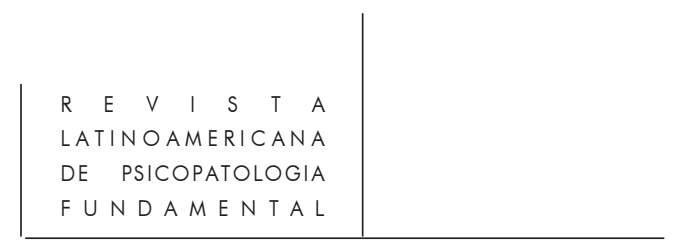

rumo novo às patologias do homem atual, transformando e operando sobre sua subjetividade.

Neste trabalho, tomando a segunda vertente, analisarei algumas das causas que operam na constituição do psiquismo, em seus aspectos mais arcaicos, e que me permitiram pensar as formas de operação e de funcionamento do pânico a partir de um ponto de vista metapsicológico. Ao abordar estas patologias, destaco a leitura freudiana, que considera a importância do pulsional, mantendo vivo o papel da sexualidade infantil sem esquecer o lugar que o trauma ocupa nas perturbações psíquicas. Se nas neuroses dirigíamos nosso olhar para as questões edípicas e seus destinos identificatórios, considerando o papel fundamental do recalque secundário, com a produção de sintomas resultantes do conflito entre instâncias intra-sistêmicas, hoje, para compreender melhor estas patologias, faz-se necessário dirigirmos nossa atenção para elementos mais arcaicos, aqueles elementos que por uma impossibilidade de tradução - o que significa que não lhes foi possível estabelecer ligação que lhes permitisse fazer sentido -, a irrupção pulsional não tem podido tramitar. Assim, estes primeiros elementos que, na teoria freudiana, corresponderiam às primeiras inscrições da representação-coisa não conseguem se engrenar numa cadeia significante e ficam excluídos, formando parte do inconsciente originário. ${ }^{1}$

Hoje em dia, vemos com surpresa o aumento de patologias nas quais o pulsional encontra sérias dificuldades para ser escoado ou tramitado, por meio da palavra ou da fantasia. Anorexias, bulimias, perturbações psicossomáticas, pânico, drogadição, adição e seitas religiosas com sentido de fanatismo, são perturbações nas quais a simbolização fracassa e que comprometem inclusive o nível de atuação no corpo ou no campo social. São perturbações nas quais os diferentes fracassos na simbolização podem ser situados na gênese e na fundação das instâncias psíquicas. A simbolização pressupõe deslocamento, união para a criação de algo novo, fundamentalmente ligação, seja de duas representações entre si ou de uma representação com um afeto. A simbolização pressupõe igualmente substituição e permite a elaboração e equivalência. Quando a simbolização falha, algo que deveria ter sido transformado, derivado, reaparece em seu estado arcaico, primitivo, puro.

Neste sentido, o pânico se apresenta como produto de uma patologia do arcaico, ou seja, produz-se um desamparo do Eu frente a uma invasão pulsional causadora de momentos de falência do aparelho psíquico. Emergem, assim, elementos da representação-coisa que deveriam ter ficado sepultados por meio do recalque primário, invadindo o Eu sem mediação da representação-palavra. Estes elementos desligados

1. Tanto Jean Laplanche quanto Piera Aulagnier insistem em revisitar os transtornos neste campo. Laplanche trabalhando o conceito de recalque primário e Piera propondo uma nova metapsicologia que transita pelo "originário, primário e secundário". 


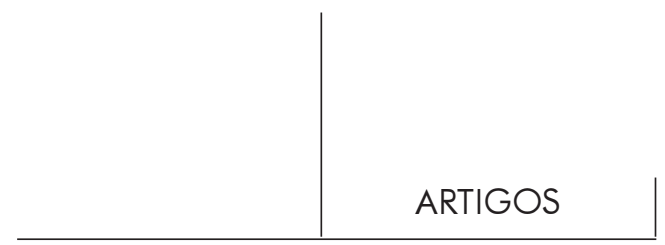

se incrustam no Eu como elementos bizarros que não encontram seu destino num fantasma, não podem ser metabolizados, não encontram escoamento na palavra e são descarregados no somático por meio de suores, taquicardia, sensação de morte eminente. Algo aparece como pura presença e nos conduz às origens das primeiras marcas, onde o inconsciente ainda não está constituído como sistema (Sigal, 2000). Estes elementos, que ficaram desligados, avançam fazendo irrupção no Eu. Eles não têm a complexidade do sintoma que permite certa estabilidade, dado que não são substituição simbólica de representações reprimidas. O sintoma tem um sentido e é produto de um conflito entre instâncias, denotando uma configuração simbólica, ou seja, o sintoma está no campo das neuroses.

Não pretendemos negar que, em alguns casos, o pânico se apresenta dentro de uma estrutura com história, como produto de um sintoma, como acontece, por exemplo, numa manifestação aguda de uma fobia (Sigal, 1997). Quando assim o é, o pânico configura-se como expressão da angústia de castração vinculada ao edípico. No entanto, o que aqui estudamos está mais próximo do conceito freudiano de neuroses atuais e, mais especificamente, das chamadas neuroses de angústia, nas quais, tal como entendo, produz-se a emergência de uma representação com uma qualidade tão primitiva, tão próxima da sensação, com uma intensidade tão próxima do puro afeto, que impede que a angústia sinal atue, o que anteciparia ao Ego algo a respeito do risco de falência.

Lembremos que, no originário, a representação do afeto e o afeto da representação são indissociáveis. Devido a um fracasso no recalque primário que deveria tê-los sepultado definitivamente, e em virtude das dificuldades para fazer os deslocamentos da representação-coisa para a representação-palavra, elementos arcaicos inscritos na psique presentificam-se como corpos estranhos sem possibilidade de tradução. Se a ligação com a palavra já tivesse ocorrido, seria possível fazer, com êxito, uma derivação desta pulsão, um deslocamento por meio do qual afastar-se-ia o temido, em um movimento metonímico ou metafórico, constituindo sintoma.

Em outras palavras, esta situação nos põe em contato com a angústia catastrófica do não-ligado, algo que escoa por um buraco, algo que escapa, uma vez que aquela marca que tem inscrição primeva aparece por uma falha no recalque primário, sem os diques sucessivos que implicariam esforços de tradução. A origem destes impedimentos encontra-se nos alicerces da formação do aparelho psíquico, estando intimamente ligados ao trauma.

É neste sentido que Laplanche nos oferece subsídios fundamentais para entender as relações mente-corpo, no interior da psicanálise, propondo um caminho para pensar a inscrição da pulsão a partir da ação do outro humano e não como derivação direta do somático no psíquico, posição que compartilho por ter me oferecido respostas para a clínica com crianças pequenas e para as patologias contemporâneas que estamos tratando. 


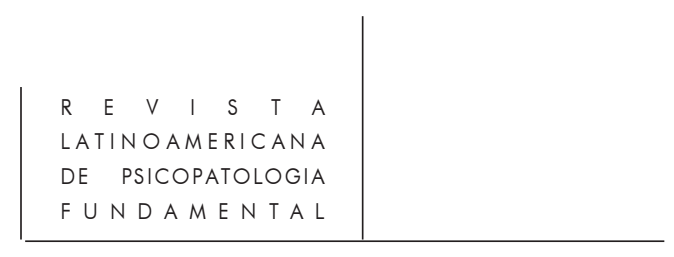

Há um assédio permanente da vivência traumática, entendendo por traumático nesta situação não um acidente, mas a forma em que a sexualidade foi implantada. Assim, a marca da sexualidade sempre determina algo de traumático: o outro da sedução originária, o adulto, implanta os significantes como numa superfície psicofisiológica na qual o inconsciente ainda não está diferenciado. Sobre estes significantes recebidos passivamente, operam as primeiras tentativas de tradução, sendo o reprimido originário os restos não traduzidos e que atuam como objeto-fonte da pulsão (Laplanche, 1980: 136).

Existem duas modalidades, segundo Laplanche (1992), por meio das quais a mãe introduz a sexualidade, seduz e erogeniza o pequeno sujeito, permitindo, desta forma, a emergência do pulsional. A implantação corresponde ao processo comum, cotidiano, neurótico e, junto a este encontramos, como sua versão violenta, a intromissão. Se a primeira permite ao indivíduo uma recaptura viva, ativa, da sexualidade materna, a intromissão introduz um elemento rebelde a toda formação metabolizável. A intromissão implica um excesso traumático que deixa o psiquismo livre de uma fixação. Permanece como corpo estranho, como objeto bizarro que se re-intromete no $\mathrm{Eu}$, desorganizando-o, às vezes pulverizando-o, deixando-o à mercê da pura intensidade de significantes que, ainda que sexuais, não têm a marca do edípico da criança, mesmo que veicule o Édipo materno. Esta invasão provoca uma amputação funcional do ego, impedindo sua função primordial que é, segundo Freud, a de assegurar o quanto possível uma percepção unitária e relativamente constante de si mesmo, diante do mundo exterior. O que caracteriza os significados inscritos por intromissão, nos diz Silvia Bleichmar (1993), é sua impossibilidade de serem fixados a algum sistema pelo recalcamento, mesmo que opere para outros elementos no aparelho psíquico. Pela violência com a qual a sexualidade foi implantada, impedese a formação de vias de escoamento e derivação, e são deixadas as janelas pelas quais estas representações avançam de forma desligada.

Os impulsos sexuais arcaicos, próprios da primeira infância, adquirem uma dimensão vertiginosa e aterrorizante - o corpo e o ser da criança foram suporte de um investimento abusivo que se torna impossível de metabolizar e simbolizar. Há uma acumulação de energia que não encontra representação que lhe sirva de suporte. Aquilo que não foi suficientemente traduzido, decomposto e recomposto pela mãe em outras configurações que fossem passíveis de serem apreendidas, encontra impossibilidade de derivação para o campo do fantasma. A sexualidade assim transmitida cria elementos sádicos e temores fusionais que permanecem desligados. Há aqui, portanto, uma outra explicação para aquilo que, na teoria kleiniana, seria explicado como um aumento da pulsão de morte considerada como inata. É na relação com o outro primordial que se origina a patologia do arcaico e a fundação do sujeito psíquico. É a mãe que - por uma falha na sua própria sexualidade, de elementos que nela própria resistiram ao processo de elaboração - passa os mesmos, sem mediação para 


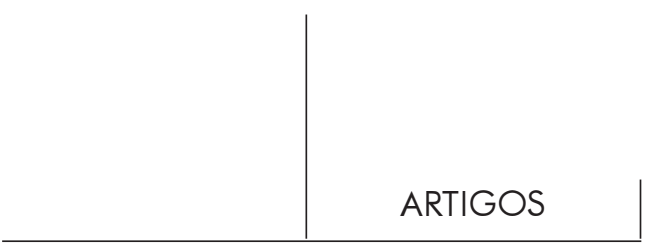

a criança, provocando uma tendência à repetição em ato do não-elaborado. Por uma falha no processo de elaboração, o qual se transmite transgeracionalmente, retorna no arcaico algo do indizível.

Este esforço teórico nos serve para repensar o nível de efetividade na cura de condutas que não configuram verdadeiros sintomas. Tentar dar sentido para estes medos, que não são substituição de nada, e sim a presença atual da angústia mesma, pareceria inútil. Por esta razão é que pensamos na possibilidade de restaurar a situação originária na cura para que, como sugere Laplanche, seja possível nos enfrentarmos novamente com os primeiros enigmas da sedução originária, abrindo caminho para a possibilidade de realizar novas ligações, para, na verdade, criar algo novo onde faltou palavra.

Frente a estes pacientes, portanto, parece infrutífera a tarefa de querer interpretar sentidos reprimidos existentes, como seria a tarefa habitual nas neuroses. É necessário que o terapeuta ofereça um aspecto ligador de sustentação. É necessário que se possibilite uma recomposição produtiva a partir de um ensamble possível que integre estes elementos que se filtram pelos buracos, produzidos pelo afinamento da membrana, que fez fracassar em parte o recalque primário, invadindo o $\mathrm{Eu}$, até que seja possível encontrar sua ligação com a representação-palavra que lhe outorgue um sentido que talvez nunca tenha tido. Tudo isto marcado e sustentado pela força da transferência.

\section{Referências}

Bleichmar, S. La fundación de lo inconsciente. Buenos Aires: Amorrortu, 1993.

Laplanche, J. Novos fundamentos em psicanálise. Buenos Aires: Amorrortu, 1980. Implantation, intromission. In La révolution copernicienne inachevée. Paris: Aubier, 1992.

Sigal, Ana M. Francis Bacon e o pânico. Uma falha no recalque primário. In: Fuks, Lucia

B., \& Ferraz, Flavio Carvalho. A clínica conta histórias. São Paulo: Departamento de Psicanálise/ Escuta, 2000.

Conversando com a psiquiatria. Das fobias à síndrome do pânico. São Paulo,

Percurso - Revista de Psicanálise, ano X, no 19, 1997.

\section{Resumos}

Este trabajo aborda la cuestión del pánico pensado como una falla de la represión primaria. Los mensajes sexuales maternos, implantados con violencia,impiden la metabolizacion, y permanecen como cuerpos extraños desligados que reaparecen sin nexo,imposibilitando su entrada en una cadena significante. En este caso los miedos no son substitucion de nada, y sí la presencia actual de los significantes no metabolizados. 
El trabajo del analista es dar la posibilidad para que se creen nuevos lazos donde faltó la palabra.

Palabras clave: Represión primaria, pánico, representación-cosa, angustia catastrófica

Ce travail aborde la question du syndrôme de panique en tant que défaut au niveau $d u$ refoulement primaire. Les messages sexuels maternels, implantés avec violence, empêchent la métabolisation et persistent comme corps étrangers non liés, qui réapparaîssent sans raison, rendant impossible leur inscription dans une chaîne signifiante. Dans ce cas, les peurs ne sont aucunement un substitution de quelque chose, mais au contraire la présence actuelle de signifiants non métabolisés. Le travail de l'analyste consiste à rendre possible la création de nouveaux liens là où la parole a manqué.

Mots clés: Refoulement primaire, panique, représentation de chose, angoisse catastrophique

This paper discusses the topic of panic seen as a "gap," or failure, in primal repression. The mother's sexual messages, violently implanted, prevent the "metabolic process" and remain as "foreign non-linked bodies" which reappear without connection and therefore cannot be placed in the chain of signifiers. In these cases, fears are not the substitution of anything but the continued presence of "non-metabolized" signifiers. The analyst's work is to enable new links to be made where there were no words.

Key words: Primal repression, panic, thing-representation, catastrophe anxiety

Versão inicial recebida em janeiro de 2001

Versão aprovada em novembro de 2001 